\title{
Superb Fairy-Wren (Malurus cyaneus) Sons and Daughters Acquire Song Elements of Mothers and Social Fathers
}

\author{
Christine Evans and Sonia Kleindorfer * \\ Animal Behaviour Lab, School of Biological Sciences, Flinders University, Adelaide, SA, Australia
}

Birdsong is regarded as a classic example of a sexually-selected trait and has been primarily studied in systems with male song. Complex solo female song is emerging from the shadows of overlooked phenomena. In males, rearing conditions affect male song complexity, and males with complex songs are often more successful at mate attraction and territorial defense. Little is known about the ontogeny or function of complex female song. Here we examine song elements in fledgling superb fairy-wrens (Malurus cyaneus) in relation to the song elements of adult tutors. Male and female superb fairy-wrens produce solo song year-round to defend a territory. We ask if sons and daughters acquire song elements from sex-specific vocal tutors. We found that sons and daughters

OPEN ACCESS

Edited by:

Michelle L. Hall,

University of Melbourne, Australia

Reviewed by:

Dianne Heather Brunton,

Massey University, New Zealand Nathaniel T. Wheelwright,

Bowdoin College, USA

*Correspondence:

Sonia Kleindorfer

sonia.kleindorfer@flinders.edu.au

Specialty section:

This article was submitted to Behavioral and Evolutionary Ecology,

a section of the journal

Frontiers in Ecology and Evolution

Received: 26 October 2015

Accepted: 27 January 2016

Published: 11 February 2016

Citation:

Evans C and Kleindorfer S (2016)

Superb Fairy-Wren (Malurus cyaneus)

Sons and Daughters Acquire Song

Elements of Mothers and Social

Fathers. Front. Ecol. Evol. 4:9.

doi: 10.3389/fevo.2016.00009 produced the song elements of their mothers and social fathers, and that sons and daughters had comparable song element repertoires at age 7-10 weeks. We conclude that sons and daughters increase their song element repertoire when vocally imitating elements from several vocal tutors, and that both sexes acquire elements from male and female vocal tutors in this system.

Keywords: superb fairy-wren, birdsong, female song, vocal learning, song element repertoire, Maluridae, vocal tutors

\section{INTRODUCTION}

Birdsong is widely regarded as a sexually-selected trait given ample evidence that complex male song is more likely to attract females and repel intruder males (Andersson, 1994; Marler and Slabbekoorn, 2004; Catchpole and Slater, 2008). There is growing evidence that female song is "common" rather than "exceptional" (Riebel et al., 2005; Garamszegi et al., 2007; Price, 2009; Odom et al., 2014), which focuses research attention on the role of sexual selection for complex female song (Price, 2015). Song complexity in females varies greatly across species (Odom et al., 2014; Price, 2015). As discussed by Price (2015): "Although female song is often treated as a discrete binary character in comparisons among species, with some species categorized as having female song and others not (e.g., Garamszegi et al., 2007; Price, 2009; Odom et al., 2014), evidence suggests that female singing can vary continuously across taxa in both expression and complexity." To date, we know very little about how this complexity in female song arises.

Female song functions for multiple purposes, including territorial defense, mate attraction, coordination of breeding activities, and female-female competition for reproductive resources (Langmore, 1998). In the superb fairy-wren (Malurus cyaneus), female song, similar to male song, has been shown to function in response to the threat of same-sex conspecific intruders in 
the territory (Kleindorfer et al., 2013; Cain and Langmore, 2015). In banded wrens (Thryophilus pleurostictus), there is support for the function of female song for communicating with their breeding partner (Hall et al., 2015), whereas the main functions of male song are mate attraction and stimulation, and territorial advertisement and defense (Kroodsma, 1976; Catchpole and Slater, 2008). Therefore, the evolution of male and female song could be under the same or different selection pressures depending on the specific context (Price, 2015).

Song can be a sexually dimorphic trait. Generally, males sing more complex songs than females (discussed in Brenowitz and Kroodsma, 1996; Catchpole and Slater, 2008). Some studies have found comparable song structure, complexity, and repertoire size in males and females (Brunton and Li, 2006; Pilowsky and Rubenstein, 2013; Schwabl et al., 2015). While females rarely have larger song repertoires than males, there are exceptions: female stripe-headed sparrows (Peucaea $r$. ruficauda) have been shown to have more complex chatter song repertoires than males (Illes, 2015), and female Australian magpies (Gymnorhina tibicen) had larger duet repertoires than males (Brown and Farabaugh, 1991). The capacity to learn complex songs is strongly influenced by the development of the neural song system (Buchanan et al., 2004). In general, male songbirds have larger high vocal center (HVC) nuclei than females (MacDougall-Shackleton and Ball, 1999; Hall et al., 2010), yet female song can be similar or more complex than male song (Illes, 2015; Schwabl et al., 2015). This suggests that a smaller HVC in female songbirds is not necessarily a constraint for learning and developing complex songs.

There is limited knowledge of song learning in females, including how females learn to sing and from whom (Riebel, 2003; Riebel et al., 2005). In species with male and female song, whereby the song may be the same or different across the sexes, both sexes are potential song tutors. When both parents sing, young birds could learn their song from both parents or from same-sex vocal tutors. Studies on captive birds show that young male and female songbirds learn primarily from same-sex vocal tutors in slate-colored boubous (Laniarius funebris; Wickler and Sonnenschein, 1989), stripebacked wrens (Campylorhynchus nuchalis; Price, 1998), and European starlings (Sturnus vulgaris; Hausberger et al., 1995). Young birds learn from both male and female song tutors in Indian Hill mynahs (Gracula religiosa; Bertram, 1970), Northern cardinals (Cardinalis cardinalis; Yamaguchi, 2001) and bluecapped cordon-bleus (Uraeginthus cyanocephalus; Geberzahn and Gahr, 2013; Lobato et al., 2015).

Our study species is the superb fairy-wren, a long-lived (up to 11 years) sedentary and territorial songbird (Rowley and Russell, 1997; Dunn and Cockburn, 1999). Both males and females sing solo chatter song year-round (Cooney and Cockburn, 1995; Cain and Langmore, 2015). The chatter song has several proposed functions including territory defense, mate attraction and within-pair communication (Cooney and Cockburn, 1995; Cockburn et al., 2009; Cain and Langmore, 2015). Recent evidence suggests that the primary function of chatter song is intrasexual competition for resources including social mates and territories (Cooney and Cockburn, 1995; Cockburn et al., 2009; Kleindorfer et al., 2013; Cain and Langmore, 2015; Cain et al., 2015). A secondary function of chatter song may be within-pair communication because females sing on the nest in response to their social male's song (Kleindorfer et al., 2016). It remains untested if males and females pair assortatively for song.

We study song element types in the subsong of fledgling superb fairy-wrens in relation to the song element types of the social father and mother, and ask if there are sex-specific vocal tutors. Individual fairy-wrens have different element types per song (Kleindorfer et al., 2013) therefore, we predict withinpair differences in chatter song element types. Within pairs, we predict that the male and female will have "shared" element types produced by both members of the pair and "withinpair unique" (hereafter "unique") element types produced by only the male or female within the pair (but not necessarily unique to the population). We predict that sons and daughters sing the "shared" parent element types because irrespective of vocal tutor type (male or female), the "shared" element types will be present in the vocal repertoire of the tutor(s). We also predict that sons and daughters produce different proportions of "unique" elements, whereby sons produce the "unique" element in the social father's element repertoire and daughters produce the "unique" element in the mother's element repertoire. This prediction rests on the idea that sons and daughters learn element types that signal their gender because birds acoustically discriminate sexes and chatter song functions for intrasexual competition (Cockburn et al., 2009; Kleindorfer et al., 2013; Cain and Langmore, 2015). Finally, we predict that the presence of helper males in natal groups will affect element repertoire size in male and female offspring. If there is sex-specific vocal tutoring, then we predict that the presence of helper males will increase element repertoire size in the subsong of sons but not daughters. If, however, the number of vocal tutors (and not their gender per se) increases element repertoire size in both sons and daughters, then we predict that the presence of helper males in natal groups increases element repertoire size in the subsong of sons and daughters.

\section{MATERIALS AND METHODS}

\section{Study Sites}

This study on song element acquisition in the superb fairywren was carried out at two field sites (1) Cleland Wildlife Park ( $\left.34^{\circ} 58^{\prime} S, 138^{\circ} 41^{\prime} \mathrm{E}\right)$ and (2) Scott Creek Conservation Park $\left(35^{\circ} 05^{\prime} \mathrm{S}, 138^{\circ} 41^{\prime} \mathrm{E}\right)$ in the Mount Lofty Ranges, South Australia. We recorded adult chatter song and fledgling subsong from 11 family groups across three field seasons (September-February 2012, 2013, 2014).

\section{Study Species}

The superb fairy-wren is an insectivorous passerine found in south-eastern Australia, and is a member of the Maluridae family (Rowley and Russell, 1997). The superb fairy-wren has a cooperative breeding system with a socially monogamous male and female pair, often assisted by one or more subordinate males (helpers) that provision the young and defend the permanent territory (Rowley, 1965; Mulder et al., 1994; Dunn et al., 1995; Rowley and Russell, 1997; Mulder, 1997; Cockburn et al., 2008). The dominant male is not always the genetic father because most broods (75-95\%) contain young sired by 
extra-pair males (Mulder et al., 1994; Cockburn et al., 2003; Colombelli-Négrel et al., 2009). We refer to the dominant male as the social father. The breeding season occurs between August and February, with 1-3 breeding attempts per year and 2-3 eggs per nest (Colombelli-Négrel and Kleindorfer, 2009). The incubation phase has a duration of 12-15 days and the nestling phase is 10-15 days (Colombelli-Négrel and Kleindorfer, 2009). Nest predation is high (e.g., 24-74\%; discussed in Rowley and Russell, 1997; Colombelli-Négrel and Kleindorfer, 2009) and once fledged, there is the risk of fledgling predation (Rowley, 1965; Cockburn et al., 2008). Most groups produce one brood of fledglings per year (Rowley and Russell, 1997). Females are uniparental incubators; all group members feed nestlings and dependent fledglings (Mulder et al., 1994; Dunn et al., 1995). Fledglings become independent of adult feeding around 4 weeks after fledging, but remain in the natal group for several months (Mulder, 1995; Rowley and Russell, 1997). Males are philopatric, remaining in the natal territory for one or more years as helper males, whereas females disperse in the first year, on average $1-10 \mathrm{~km}$ and 11.8 territories removed from the natal territory (Rowley, 1965; Cooney and Cockburn, 1995; Mulder, 1995; Cockburn et al., 2003; Double et al., 2005). Adult males and females are sexually dichromatic and can be easily distinguished in the field. Recently fledged young of both sexes resemble adult females (Mulder, 1995).

There are eight vocalizations described for the superb fairywren (Rowley, 1965; Kleindorfer et al., 2013). We focus on chatter song (Type I song) because it is the most common song produced year-round by both male and female superb fairy-wrens for territorial and resource defense (Langmore and Mulder, 1992; Cooney and Cockburn, 1995; Kleindorfer et al., 2013; Cain and Langmore, 2015). The chatter song is a variable, complex song that consists of $\sim 8$ structurally distinct element types produced $\sim 50$ times per song for a duration of $\sim 3 \mathrm{~s}$ (Langmore and Mulder, 1992; Kleindorfer et al., 2013). Fledglings begin singing subsong from 4 weeks after fledging (Rowley, 1965; Langmore and Mulder, 1992). It is not known when fledgling subsong crystallizes, but 1 -year old birds sing full adult song (Rowley, 1965). Adult males sing longer, more complex songs than females in some populations (Kleindorfer et al., 2013). Males also have a larger song repertoire than females: males sing chatter song and trill song (Type II song) to attract extrapair copulations (Langmore and Mulder, 1992; Cooney and Cockburn, 1995; Dalziell and Cockburn, 2008; Cockburn et al., 2009; Colombelli-Négrel et al., 2011). There is evidence that male trill song is learned: introductory elements of trill song were more similar between males and their social fathers than males and their genetic fathers; males that dispersed from the natal territory acquired the local trill song dialect (Blackmore, 2002). Furthermore, sons have been shown to learn Type II song (similar to superb fairy-wren trill song) from their social fathers in the splendid fairy-wren (M. splendens), a closely-related Malurus species (Greig et al., 2012).

\section{Nest Monitoring}

We monitored a total of 125 superb fairy-wren nests over 3 years. Nests were monitored every 2-4 days to check the status of the nest (building, eggs, nestlings, fledged) and nesting outcome (eggs depredated, eggs abandoned, nestlings depredated, nestlings abandoned, nestlings fledged). Of these 125 nests, 82 were depredated (65\%), and 19 nests produced fledglings (15\%). In this study, we analyzed song recordings for 11 nests (49 birds) for which we have recordings of both parental chatter song (male and female; $N=22$ birds), helper males $(N=9)$ as well as all offspring $(N=17)$. For each nest, we had a minimum of three song recordings per individual bird (dominant male, dominant female, helper male, fledged young).

Of the 31 adult birds for which we have song recordings, we color banded and measured 18 birds using target mist-netting. We banded at least one dominant male or female at 10 nests and six helper males at the five nests with helper males. For individuals that were not banded, we were certain of their identity based on group size and composition and the interactions of unbanded birds with banded birds (e.g., group foraging together, feeding fledglings). Nine out of 11 nests contained a single unbanded bird; one nest had an unbanded dominant male and female; one nest had an unbanded dominant female and helper male. Each captured individual was marked with a unique combination of plastic color bands and a numbered aluminum band provided by the Australian Bird and Bat Banding Scheme (ABBBS). Nestlings were banded 7-8 days after hatching.

We sexed the fledglings using the standard avian sexing method outlined by Griffiths et al. (1998), using primers P8 (5' CTC- CCAAGGATGAGRAAYTG-3') and P2 (5'-TCTGCATCGCTAAATCCTTT- $3^{\prime}$ ) with modifications to the protocol as follows. We carried out PCR amplification in a total volume of $24 \mu \mathrm{l}$ with PCR reagents in following final concentrations: 1 $\mathrm{X} \mu \mathrm{M}$ MRT buffer, $0.2 \mu \mathrm{M}$ of each primer, 0.5 units Immolase and between 10 and 100 ng DNA. PCR conditions were an initial denaturing step at $94^{\circ} \mathrm{C}$ for $10 \mathrm{~min}$, followed by 35 cycles of $94^{\circ} \mathrm{C}$ for $45 \mathrm{~s}, 48^{\circ} \mathrm{C}$ for $45 \mathrm{~s}$, and $72^{\circ} \mathrm{C}$ for $45 \mathrm{~s}$. The program was completed with a final run of $72^{\circ} \mathrm{C}$ for $5 \mathrm{~min}$ and $25^{\circ} \mathrm{C}$ for $2 \mathrm{~min}$. Of the 17 fledglings, eight were male and nine were female.

The research was approved by the Animal Welfare Committee of Flinders University (permit number E386), which operates under the Animal Welfare Act 1985 (SA). Permit to undertake scientific research in SA was granted by the SA Department of Environment, Water and Natural Resources (permit number Z24699-11). All birds were banded under permit (banding authority number 2601) from the Australian Bird and Bat Banding Scheme.

\section{Song Recordings}

We recorded the chatter song of 11 dominant pair males, 11 dominant pair females, nine helper males, eight sons, and nine daughters, from 11 nests. We recorded adult birds opportunistically throughout the breeding season. We recorded the song of fledgling birds at a distance of 5-10 $\mathrm{m}$ from the bird every 14 days for 8 weeks post-fledging. Recordings were made with a Telinga Twin Science parabolic microphone (Telinga Microphones, Sweden) connected to a portable Sound Device 722 digital audio recorder (Sound Devices, USA). Sound files were recorded as broadcast wave files (24 bit, $48 \mathrm{kHz}$ ). 


\section{Acoustical Analyses}

We transcribed all sound files to an Apple Macpro (Apple, USA) for editing with Amadeus Pro 2.1.2 (HairerSoft, Switzerland) and analysis with Raven Pro 1.5 (Charif et al., 2010). Spectrograms were created for 3-5 songs per individual using the Hann algorithm (filter bandwidth $270 \mathrm{~Hz}$, size 256 samples, time grid overlap 50\%, grid resolution $2.67 \mathrm{~ms}, 188 \mathrm{~Hz}$, DTF 256 samples). We scored the number of different element types per song for every bird. We refer to the number of different element types per bird, summed over the 3-5 songs analyzed, as the song element repertoire. In this study, we did not quantify the absolute element repertoire size. Using the available data of 3-5 songs per individual, there was no statistical association between the number of songs analyzed per bird and the element repertoire size (data available upon request). We refer to the combined number of different element types between two or more individuals (for example, the pair) as song element diversity. We define an element in the song as a single, continuous trace on a spectrogram. We created an element library (Figure 1) based on the existing element classifications developed by Langmore and Mulder (1992), Blackmore (2002), Dalziell and Cockburn (2008), Colombelli-Négrel et al. (2011) and Kleindorfer et al. (2013), and comparing these classifications of elements to songs of our monitored populations. We identified 10 element types that have previously been classified in different populations $(\mathrm{A}, \mathrm{F}, \mathrm{O}, \mathrm{P}, \mathrm{Q}, \mathrm{R}, \mathrm{T}, \mathrm{U}, \mathrm{V}, \mathrm{W}$,$) and 6$ new elements found in our populations (FL, G, K, L, Z, ZN). Within pairs, we identified element types that were present in both the male and the female songs; these element types are referred to as "shared" elements. Within pairs, we identified element types that were present in either the male or the female; these element types are referred to as "within-pair unique elements" (hereafter referred to as "unique"; we note that within-pair "unique" elements may occur in other fairy-wren individuals and hence are not "unique" to the individual but just within the pair).

We used spectrogram cross-correlation (SPCC) analysis to examine the similarity between different element types, using five examples from different individuals per element type (Raven Pro 1.5, Cornell Lab of Ornithology; band-pass filtered from 500 to $12000 \mathrm{~Hz}$ ). SPCC produces a matrix of similarity (S), which we transformed into a matrix of distance (D) using the transformation $[\mathrm{D}=(1-\mathrm{S})$ 0.5]. This matrix was evaluated by principal coordination analysis (PCoA) using the $\mathrm{R}$ package for multivariate and spatial analysis, version 4.0 (Casgrain and Legendre, 2001), as outlined in Colombelli-Négrel et al. (2012). The PCoA gives several coordinate values per element and the first five coordinate values explain most of the data set, which we used as similarity values (Baker and Logue, 2003). To determine if the assigned element categories were significantly different from one another, we averaged the five PCoA coordinate values into a single measure and analyzed the mean coordinate values per element type in a univariate ANOVA using IBM SPSS 22 (SPSS Inc, Chicago, USA). The 16 different element types were significantly different $\left[F_{(14,60)}=1.919, P=0.042\right]$. We used these element categories to classify the different element types per song, and the song element repertoire per individual (Figure 1). We printed spectrograms and assigned element types visually according to the library of element categories. This method was chosen because humans outperform machines for tasks like the visual recognition of element types (Law and Ahn, 2011). Three people (two naïve assessors and the person who scored the spectrograms for this study) independently reviewed 20 randomly chosen spectrograms (identity of bird unknown) and classified the different element types. The average similarity rate was $95.7 \%$ for the scoring of the number of different element types.

\section{Statistical Analyses}

We used IBM SPSS 22 for statistical analyses of song element types. We examined the data for normality and homogeneity of variance. The variables "different element types per social father" and "different element types per mother" were squareroot transformed, and "number of unique paternal elements" and "number of unique maternal elements" were reflect and square-root transformed to satisfy requirements of normality for parametric tests.

\section{RESULTS}

\section{Song Element Repertoire of Social Father and Mother Pairs}

There were 16 different song element types in the repertoire of the 11 males and 11 females that were social parents (Figure 1). No element was exclusive to males or females in the study population, and hence there were no "male elements" vs. "female elements.” Element repertoire size was statistically comparable between social fathers $(8.5 \pm 0.6$; mean \pm se) and mothers $(8.5 \pm$ $0.4)$ for 11 pairs [paired samples $t$-test: $t_{(10)}=0.064, P=0.950$ ]. The element diversity (combined element repertoire of social father and mother) between pairs varied (mean: $10.7 \pm 0.4$, range: 9-14).

Within each pair, $60.2 \pm 3.7 \%$ of song elements were present in both the social father and mother song, and these elements are referred to as "shared." The percentage of elements present in only the social father or mother song was $39.8 \pm 3.7 \%$, and these elements are referred to as "unique." The mean number of "shared" element types within pairs was $6.4 \pm 0.3$ element types. The number of "unique" elements did not differ significantly between social fathers $(2.2 \pm 0.6)$ and mothers $[2.2 \pm 0.3$; paired samples $t$-test: $t_{(11)}=0.530, P=0.608$; Figure 2].

\section{Song Element Repertoire of the Sons and Daughters}

Song element repertoires were comparable in sons $(9.3 \pm 0.8)$ and daughters [10.2 \pm 0.6 ; independent samples $t$-test per nest: $t_{(12)}=-0.813, N=14$ birds, $P=0.432$; Figure 2]. The average number of different element types per brood varied (mean: $8.9 \pm$ 0.5 , range: $6-11.5$ ). There was no significant correlation between the element diversity of the social father and mother, and brood [linear regression: $F_{(1,9)}=0.119, r=0.114, P=0.738$ ] or group (parents + helper male) and brood [linear regression: $\left.F_{(1,9)}=0.028, r=0.955, P=0.871\right]$. 


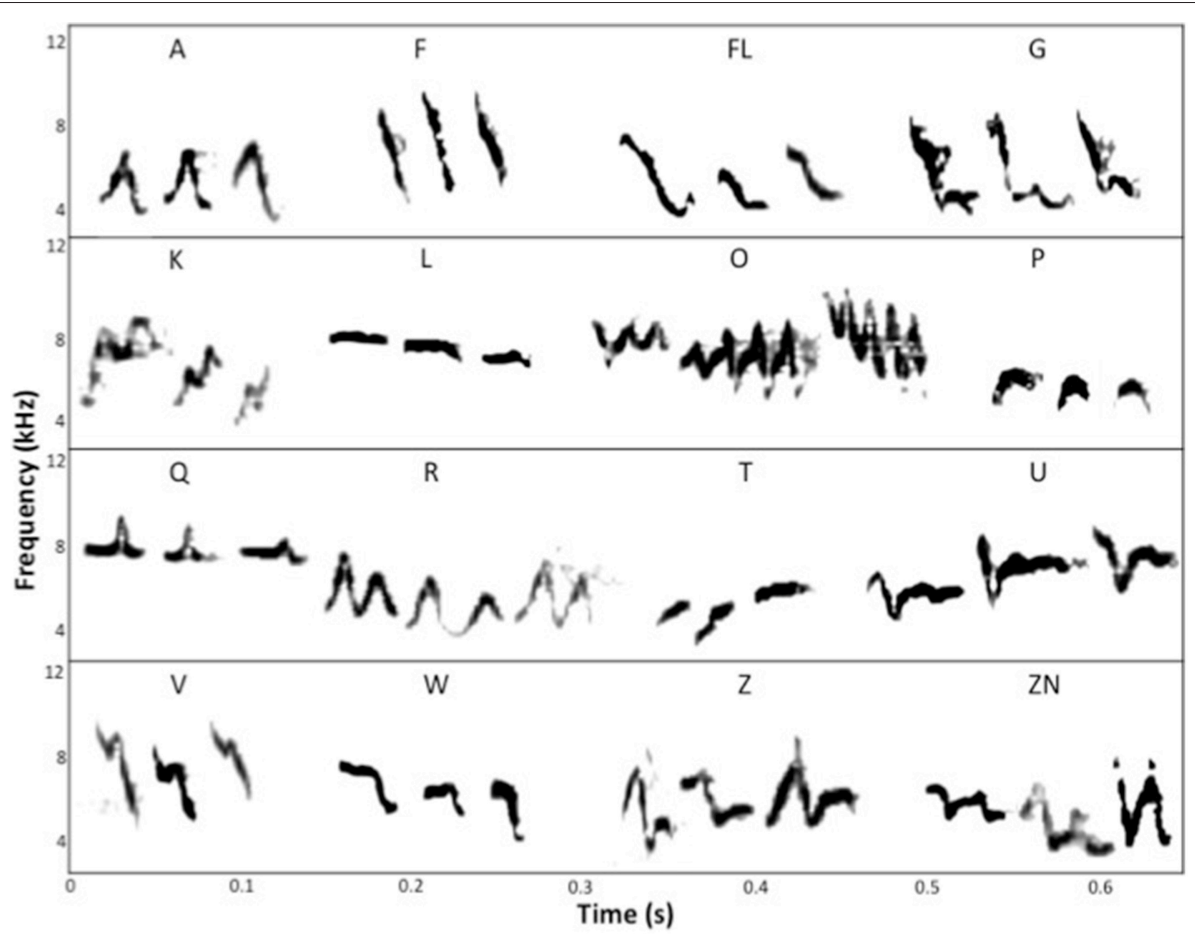

FIGURE 1 | Spectrograms of different element types identified in the chatter song of superb fairy-wrens (Malurus cyaneus) from populations in the Mount Lofty Ranges region of South Australia. Each element type is illustrated with three exemplars. The elements identified in these populations include both existing element classifications and novel element types. The existing element types are: A, F, O, P, Q, R, T, U, V, W. The novel element types found in the studied populations are: FL, G, K, L, Z, ZN.



FIGURE 2 | Spectrograms of chatter song of a family group of superb fairy-wrens: (A) social father; (B) mother; (C) son, aged 9 weeks; (D) daughter, aged 9 weeks. 


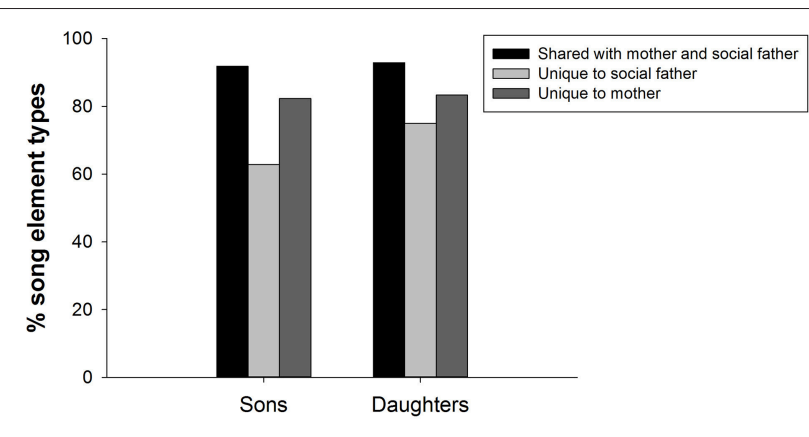

FIGURE 3 | The mean percentage of different song element types in the element repertoires of fledged superb fairy-wren sons $(N=8)$ and daughters $(\boldsymbol{N}=\mathbf{9})$. Bars show the percentage of elements in the songs of sons and daughters that were "shared" with the social father and mother, "unique" to the paternal song, or "unique" to the maternal song.

\section{"Shared" and "Unique" Song Elements Present in Sons and Daughters}

The number of "shared" elements from their social parent vocal tutors was comparable in sons $(5.6 \pm 0.4)$ and daughters (6.5 \pm 0.2 ; sign test: $P>0.999$; Figure 3$)$. Of the total song elements produced by fledglings, there was no significant difference between the percentage of "unique" maternal elements $(86.0 \pm 10.3 \%)$ and the percentage of "unique" paternal elements $(64.3 \pm 11.2 \%$; sign test: $P=0.125)$. Fledglings that sang "unique" element types from both the mother and social father produced a higher number of different element types (10.3 \pm 0.6) than fledglings that did not sing "unique" element types from both social parents [7.3 \pm 0.9 ; independent samples $t$-test: $\left.F_{(10)}=0.417, t=-2.915, P=0.015\right]$. Looking at each sex separately (using the average per sex per nest), sons did not differ significantly in the number of "unique" maternal (1.9 \pm $0.2)$ or paternal $(1.3 \pm 0.5)$ elements (sign test: $P=0.289)$, and daughters did not differ significantly in the number of "unique" maternal $(1.2 \pm 0.3)$ or paternal $(1.5 \pm 0.3)$ elements (sign test: $P>0.999$; Figure 3). Five fledglings had "unique" element types $(1.4 \pm 0.2)$ not present in the song repertoire of the social father, mother, or helper male.

\section{Song Element Repertoire of Helper Male in Relation to Dominant Pair Male and Female}

Of the 11 nests, five nests had helper males (one nest had one helper male and four nests had two helper males). Among helper males, most element types $(56.4 \% \pm 2.8)$ were "shared" with the dominant pair, some elements were the same as the "unique" maternal element types $(15.3 \% \pm 3.9)$, some elements were the same as the "unique" paternal element types $(13.6 \% \pm 3.9)$, and some were "unique" to the helper male $(14.6 \% \pm 3.0)$. Expressed as a number rather than a percentage, helper males had $1.6 \pm$ 0.4 "unique" element types that were different from the "unique" element types in the pair male and female. The number of different element types produced by all adult birds (pair + helper males) was not significantly different between nests with and without helper males [independent samples $t$-test: $t_{(9)}=-1.393$, $P=0.197]$.

\section{Song Element Repertoire of Sons and Daughters in Relation to Groups with and Without Helper Males}

There was no significant difference between the element repertoire size of fledglings in groups with helper males $(9.6 \pm$ $1.0)$ and without helper males $[9.1 \pm 0.7$; independent $t$-test: $\left.t_{(10)}=-0.372, P=0.718\right]$. Examining each sex separately, the element repertoire size of sons in groups with helper males was comparable with the element repertoire size of sons in groups without helper males [independent $t$-test: $t_{(6)}=-0.551, P=$ $0.601]$; the element repertoire size of daughters in groups with helper males was comparable with the element repertoire size of daughters in groups without helper males (Mann-Whitney $U$-test: $U=4.000, z=-0.221, P=0.825$; Figure 4).

\section{DISCUSSION}

The main findings of this study are that (1) the chatter song in nesting pairs of superb fairy-wrens contained "shared" element types found in both male and female chatter song as well as "unique" element types produced by only one parent (male or female); (2) sons and daughters sang "shared" and "unique" song element types of both social father and mother (parental) vocal tutors; (3) sons and daughters had comparable song element repertoires at age 7-10 weeks; (4) the presence of helper males did not increase the element repertoire size of fledglings. These findings suggest that sons and daughters acquire song element types from both male and female tutors. Because we did not assess maximum repertoire size in adult or fledgling birds or examine song element types of neighboring birds, sons and daughters may produce vocal elements from individuals outside their social group.

\section{Within-Pair "Shared" and "Unique" Song Element Types}

Males and females within-pairs produced element types that were either present in the chatter song of both parents, or element types present in only one parent. Repertoire composition was variable across individuals, with no consistent sex differences in the presence or absence of particular element types. Other studies have found both sex-specific and individual-specific element types. Male and female bellbirds (Anthornis melanura) shared $20 \%$ of syllable types but most syllables $(80 \%)$ were sex-specific at a population level (Brunton and $\mathrm{Li}, 2006$ ). In comparison, male and female Australian magpies rarely shared syllable types for carol songs, and syllable repertoires were highly individualspecific (Brown and Farabaugh, 1991). Our study was limited to the comparison of shared and unique elements within pairs and not at the population level. At the population level, there were sex differences in the number of particular element types; similar to our study, there were no sex-specific element types (Kleindorfer et al., 2013).

\section{Sons and Daughters Sang Element Types of Mothers and Social Fathers}

Our finding that offspring produced the "unique" maternal and "unique" paternal element types supports the idea that 


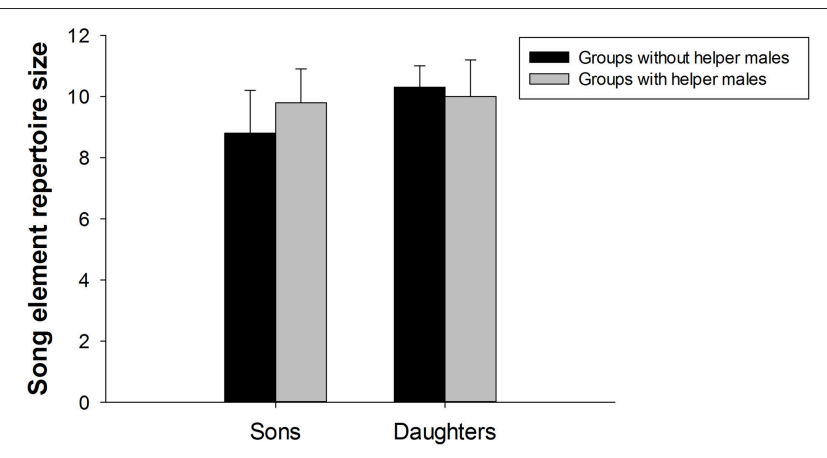

FIGURE 4 | The song element repertoire size (number of different element types; mean $\pm \mathrm{se})$ in fledged superb fairy-wren sons $(N=8)$ and daughters $(\mathbf{N}=\mathbf{9})$. Bars show the element repertoire size in sons and daughters from groups without helper males (social father, mother and brood) and groups with helper males (social father, mother, helper males, and brood).

superb fairy-wren mothers and social fathers were vocal tutors for sons and daughters. However, we did not compare the parental element repertoire with neighboring individuals, so fledglings could also have learned these element types from individuals other than the social parents. Because we did not cross-foster clutches, we cannot rule out innate components of element repertoire emergence in sons and daughters. It is well-established that oscine passerines learn their songs (Brenowitz, 1991; Brainard and Doupe, 2002; Pfenning et al., 2014), and previous research has shown vocal imitation in fairy-wrens (Greig et al., 2012; Colombelli-Négrel et al., 2012). Therefore, it is reasonable to conclude that superb fairy-wren fledgling song elements were learned. The finding that sons and daughters produced "unique" elements from mothers and social fathers is an exciting finding because few studies to date have tested if both sexes may be vocal tutors for young male and female birds. Yamaguchi (2001) showed that captive Northern cardinals learn multiple song types from same-sex and opposite-sex vocal tutors, and Geberzahn and Gahr (2013) found that male and female blue-capped cordon-bleus also learn song from either sex, irrespective of the fact that males have larger syllable-type song repertoires than females. This is in contrast to other studies, which found that young birds showed a preference for learning vocalizations from same-sex vocal tutors (Wickler and Sonnenschein, 1989; Hausberger et al., 1995; Price, 1998).

Learning from two vocal tutors may increase an individual's chances of acquiring complex song. A wealth of research has shown that song complexity is an honest signal of male quality (Buchanan et al., 2004; Spencer et al., 2005; Schmidt et al., 2013), important for female mate choice (Catchpole, 1980; reviewed in Byers and Kroodsma, 2009). In superb fairy-wrens, different male song types predicted extra-pair fertilisations (Dalziell and Cockburn, 2008), and sexes had different element complexity (Kleindorfer et al., 2013). A theoretical framework for functions of female song complexity mostly focuses on resource defense (Cain and Langmore, 2015; Illes, 2015). Evidence for increased female fitness associated with complex female song comes from a few studies: older female alpine accentors (Prunella collaris) that sang more complex songs had larger clutch sizes (Langmore et al., 1996), and female European starlings with complex song had repeatable reproductive performance across years (Pavlova et al., 2010). Here we show that offspring had larger song element repertoires when exposed to element types of different vocal tutors, but we did not examine fledgling song complexity. We expect that fledglings with greater song complexity will have greater fitness.

The cooperative breeding system of the superb fairy-wren means that young birds interact with all group members (Mulder, 1995; Rowley and Russell, 1997). Social interactions with vocal tutors have been shown to facilitate song learning (Baptista and Petrinovich, 1984, 1986; Beecher et al., 1994; Beecher and Burt, 2004). Research on zebra finches (Taeniopygia guttata) found that social interactions influenced song tutor choice: young males preferred male vocal tutors that provided a greater amount of parental care (Williams, 1990), and chose fathers over unrelated males (Eales, 1987). The role of social interactions for the attention of young birds for particular adult vocal tutors remains to be tested in our system. All adults provisioned all offspring, and fledglings produced "shared" and "unique" parental element types. Although groups with helper males had on average one more "unique" element type per group, we did not find that fledglings of groups with helper males had a larger element repertoire than fledglings of groups without helper males. Helper males tend to be sons from a previous brood, and therefore these males also (largely) acquire their elements from the mother and social father. Perhaps the within-family element diversity is maintained rather than enhanced in the presence of helper males who may act as additional tutors.

\section{Song Element Repertoire in Sons and Daughters}

Previous research showed higher song complexity in adult males than females (Kleindorfer et al., 2013). It is possible that daughters lose element types with age, as we did not find sex differences in fledgling element repertoire size. Such a decrease in repertoire size with age has been found in female blue-capped cordon-bleus (Lobato et al., 2015). Males may have a longer sensory acquisition phase than females and acquire more element types over a longer timeframe, which is another explanation for why adult males have more complex song than females. Such a process has been proposed for Northern cardinals and bluecapped cordon-bleus (Yamaguchi, 2001; Geberzahn and Gahr, 2013; Lobato et al., 2015). All we can say at present is that we found no sex differences in fledgling song element repertoire, so therefore it is likely that sex differences emerge later in the superb fairy-wren.

Although sons and daughters sang element types of both parents, pairs with higher element diversity did not always have offspring with higher element diversity. This suggests that the development of complex song could be influenced by factors other than the element diversity of parents (Buchanan et al., 2003, 2004; Spencer et al., 2005; Schmidt et al., 2013). Rearing conditions can influence song learning and development. There is ample evidence for negative effects of developmental stress on song learning and complexity in male songbirds. Research 
into zebra finches found that developmentally stressed males had smaller HVC nuclei (area of brain associated with production of complex songs), and therefore lower song complexity (Buchanan et al., 2004; Spencer et al., 2005). Similarly, swamp sparrows (Melospiza georgiana) that received less food early in life had poor copy accuracy and a smaller repertoire size, suggesting that malnutrition affects song learning (Nowicki et al., 2002). Therefore, the observed variation in the average number of different elements across broods in this study could be explained by nutritional or environmental stress (Nowicki et al., 2002; Buchanan et al., 2004; Spencer et al., 2005), which we did not measure.

Exposure to song during development may have contributed to differences in the number of elements between broods. Offspring were exposed to both adult male and female song (Evans, unpublished data). However, we did not test for differences in song rate between adult males and females in the presence of fledged young in this study. Variation in song rates and subsequent exposure to song may influence song learning and copy accuracy (but see Hultsch et al., 1999). In a separate study of incubation calling in superb fairy-wrens, Kleindorfer et al. (2014) found that increased call rates resulted in higher vocal copy accuracy of chicks. Perhaps some of the variation in the number of chatter song elements produced by young birds is explained by the song rate of the parental birds (purported vocal tutors).

\section{CONCLUSION}

There is much interest in the function of female song, its complexity, and whether it is also subject to sexual selection. In this study we focused on the acquisition of song elements in sons and daughters in a system where both sexes produce solo song year round as adults. Sons and daughters produced vocal elements that included the same proportion of "shared" and "unique" elements between the pair male and female attending

\section{REFERENCES}

Andersson, M. (1994). Sexual Selection. Princeton, NJ: Princeton University Press. Baker, M. C., and Logue, D. M. (2003). Population differentiation in a complex bird sound: a comparison of three bioacoustical analysis procedures. Ethology 109, 223-242. doi: 10.1046/j.1439-0310.2003.00866.x

Baptista, L. F., and Petrinovich, L. (1984). Social interaction, sensitive phases and the song template hypothesis in the white-crowned sparrow. Anim. Behav. 32, 172-181. doi: 10.1016/S0003-3472(84)80335-8

Baptista, L. F., and Petrinovich, L. (1986). Song development in the white-crowned sparrow: social factors and sex differences. Anim. Behav. 34, 1359-1371. doi: 10.1016/S0003-3472(86)80207-X

Beecher, M. D., and Burt, J. M. (2004). The role of social interaction in bird song learning. Curr. Dir. Psychol. 13, 224-228. doi: 10.1111/j.09637214.2004.00313.x

Beecher, M. D., Campbell, S. E., and Stoddard, P. K. (1994). Correlation of song learning and territory establishment strategies in the song sparrow. Proc. Natl. Acad. Sci. U.S.A. 91, 1450-1454. doi: 10.1073/pnas.91.4.1450

Bertram, B. (1970). The vocal behaviour of the Indian hill mynah. Anim. Behav. Monogr. 3, 81-192. doi: 10.1016/S0066-1856(70)80003-6 the nest. Given that male and female song elements were present in the song of the sons and daughters, we conclude that the diversity of element types in the combined "parental repertoire" was copied and produced by the entire brood, resulting in a "family vocal repertoire." This finding raises several new lines of inquiry into song patterns within families. We conclude with two exciting questions here: (1) Do social partners have assortative pairing for element diversity ("shared" and "unique") to increase song complexity in their offspring, and do offspring with higher vocal complexity have greater fitness? (2) Do social partners have disassortative pairing for "shared" elements to reduce inbreeding?

\section{AUTHOR CONTRIBUTIONS}

CE and SK designed the study, developed the methodology, performed the analysis, and wrote the manuscript. CE collected the data.

\section{FUNDING}

The project was funded by the Nature Foundation of South Australia, Birds South Australia, and the ANZ Trustees Foundation-Holsworth Wildlife Research Endowment Grant.

\section{ACKNOWLEDGMENTS}

We thank Cleland Wildlife Park for access to the study site. Special thanks to Katharina Mahr for field assistance, and Diane Colombelli-Négrel for help with the statistical analysis of the element library and constructive discussion. We also thank the BirdLab at Flinders University for constructive discussion and scoring of element types. We thank Guest Associate Editors Michelle Hall and Naomi Langmore for the opportunity to contribute to this special issue, and for organising the symposia at Behaviour 2015.

Blackmore, C. J. (2002). Male Song and the Dawn Chorus of the Superb Fairy-Wren. M.Phil. thesis, Australian National University.

Brainard, M. S., and Doupe, A. J. (2002). What songbirds teach us about learning. Nature 417, 351-358. doi: 10.1038/417351a

Brenowitz, E. A. (1991). Evolution of the vocal control system in the avian brain. Semin. Neurosci. 3, 399-407. doi: 10.1016/1044-5765(91)90030-R

Brenowitz, E. A., and Kroodsma, D. E. (1996). "The neuroethology of birdsong," in Ecology and Evolution of Acoustic Communication in Birds, eds D. E. Kroodsma and E. H. Miller (Ithaca, NY: Cornell University Press), 285-304.

Brown, E. D., and Farabaugh, S. M. (1991). Song sharing in a group-living songbird, the Australian magpie, Gymnorhina tibicen. Part III. Sex specificity and individual specificity of vocal parts in communal chorus and duet songs. Behaviour 118, 244-274. doi: 10.1163/156853991X00319

Brunton, D. H., and Li, X. (2006). The song structure and seasonal patterns of vocal behavior of male and female bellbirds (Anthornis melanura). Ethology 24, 17-25. doi: 10.1007/s10164-005-0155-5

Buchanan, K. L., Leitner, S., Spencer, K. A., Goldsmith, A. R., and Catchpole, C. K. (2004). Developmental stress selectively affects the song control nucleus HVC in the zebra finch. Proc. R. Soc. Lond. B. Biol. 271, 2381-2386. doi: $10.1098 /$ rspb.2004.2874 
Buchanan, K. L., Spencer, K. A., Goldsmith, A. R., and Catchpole, C. K. (2003). Song as an honest signal of past developmental stress in the European starling (Sturnus vulgaris). Proc. R. Soc. Lond. B. Biol. 270, 1149-1156. doi: 10.1098/rspb.2003.2330

Byers, B. E., and Kroodsma, D. E. (2009). Female mate choice and songbird song repertoires. Anim. Behav. 77, 13-22. doi: 10.1016/j.anbehav.2008.10.003

Cain, K. E., Cockburn, A., and Langmore, N. (2015). Female song rates in response to simulated intruder are positively related to reproductive success. Front. Ecol. Evol. 3:119. doi: 10.3389/fevo.2015.00119

Cain, K. E., and Langmore, N. E. (2015). Female and male song rates across breeding stage: testing for sexual and nonsexual functions of female song. Anim. Behav. 109, 65-71. doi: 10.1016/j.anbehav.2015.07.034

Casgrain, P., and Legendre, P. (2001). The R Package for Multivariate and Spatial Analysis, version 4.0 D6-User's Manual. Montreal: Departament de sciences biologiques: Université de Montreal.

Catchpole, C. K. (1980). Sexual selection and the evolution of complex songs among European warblers of the genus Acrocephalus. Behaviour 74, 149-165. doi: 10.1163/156853980X00366

Catchpole, C. K., and Slater, P. J. B. (2008). Bird Song: Biological Themes and Variations, 2nd Edn. Cambridge: Cambridge University Press. doi: 10.1017/CBO9780511754791

Charif, R. A., Waack, A. M., and Strickman, L. M. (2010). Raven Pro 1.4 User's Manual. Ithaca, NY: Cornell Laboratory of Ornithology.

Cockburn, A., Dalziell, A. H., Blackmore, C. J., Double, M. C., Kokko, H., Osmond, H. L., et al. (2009). Superb fairy-wren males aggregate into hidden leks to solicit extragroup fertilizations before dawn. Behav. Ecol. 20, 501-510. doi: 10.1093/beheco/arp024

Cockburn, A., Osmond, H. L., Mulder, R. A., Green, D. J., and Double, M. C. (2003). Divorce, dispersal and incest avoidance in the cooperatively breeding superb fairy-wren Malurus cyaneus. J. Anim. Ecol. 72, 189-202. doi: 10.1046/j.1365-2656.2003.00694.x

Cockburn, A., Sims, R. A., Osmond, H. L., Green, D. J., Double, M. C., and Mulder, R. A. (2008). Can we measure the benefits of help in cooperatively breeding birds: the case of superb fairy-wrens Malurus cyaneus? J. Anim. Ecol. 77, 430-438. doi: 10.1111/j.1365-2656.2007.01351.x

Colombelli-Négrel, D., Hauber, M. E., Robertson, J., Sulloway, F. J., Hoi, H., Griggio, M., et al. (2012). Embryonic learning of vocal passwords in superb fairy-wrens reveals intruder cuckoo nestlings. Curr. Biol. 22, 2155-2160. doi: 10.1016/j.cub.2012.09.025

Colombelli-Négrel, D., and Kleindorfer, S. (2009). Nest height, nest concealment, and predator type predict nest predation in superb fairywrens (Malurus cyaneus). Ecol. Res. 24, 921-928. doi: 10.1007/s11284-0080569-y

Colombelli-Négrel, D., Robertson, J., and Kleindorfer, S. (2011). Risky revelations: superb Fairy-wrens Malurus cyaneus respond more strongly to their mate's alarm song. J. Ornithol. 12, 127-135. doi: 10.1007/s10336-0100557-1

Colombelli-Négrel, D., Schotfeldt, B. E., and Kleindorfer, S. (2009). High levels of extra-pair paternity in Superb Fairy-wrens in South Australia despite low frequency of auxiliary males. Emu 109, 300-304. doi: 10.1071/MU09035

Cooney, R., and Cockburn, A. (1995). Territorial defence is the major function of female song in the Superb Fairy-wren, Malurus cyaneus. Anim. Behav. 49, 1635-1647. doi: 10.1016/0003-3472(95)90086-1

Dalziell, A. H., and Cockburn, A. (2008). Dawn song in superb fairy-wrens: a bird that seeks extrapair copulations during the dawn chorus. Anim. Behav. 75, 489-500. doi: 10.1016/j.anbehav.2007.05.014

Double, M. C., Peakall, R., Beck, N. R., and Cockburn, A. (2005). Dispersal, philopatry, and infidelity: dissecting local genetic structure in superb fairywrens (Malurus cyaneus). Evolution 59, 625-635. doi: 10.1554/04-166

Dunn, P. O., and Cockburn, A. (1999). Extrapair mate choice and honest signaling in cooperatively breeding superb fairy-wrens. Evolution 53, 938-946. doi: $10.2307 / 2640733$

Dunn, P. O., Cockburn, A., and Mulder, R. A. (1995). Fairy-wren helpers often care for young to which they are unrelated. Proc. R. Soc. Lond. B. Biol. 259, 339-343. doi: $10.1098 / \mathrm{rspb} .1995 .0050$

Eales, L. A. (1987). Do zebra finch males that have been raised by another species still tend to select a conspecific song tutor? Anim. Behav. 35, 1347-1355. doi: 10.1016/S0003-3472(87)80007-6
Garamszegi, L. Z., Pavlova, D. Z., Eens, M., and Møller, A. P. (2007). The evolution of song in female birds in Europe. Behav. Ecol. 18, 86-96. doi: 10.1093/beheco/arl047

Geberzahn, N., and Gahr, M. (2013). Song learning in male and female Uraeginthus cyanocephalus, a tropical songbird species. J. Comp. Psychol. 127, 352. doi: 10.1037/a0033154

Greig, E. I., Taft, B. N., and Pruett-Jones, S. (2012). Sons learn songs from their social fathers in a cooperatively breeding bird. Proc. R. Soc. Lond. B. Biol. 279, 3154-3160. doi: 10.1098/rspb.2011.2582

Griffiths, R., Double, M. C., Orr, K., and Dawson, R. J. (1998). A DNA test to sex most birds. Mol. Ecol. 7, 1071-1075. doi: 10.1046/j.1365-294x.1998.00389.x

Hall, M. L., Rittenbach, M. R. D., and Vehrencamp, S. L. (2015). Female song and vocal interactions with males in a neotropical wren. Front. Ecol. Evol. 3:12. doi: $10.3389 /$ fevo.2015.00012

Hall, Z. J., MacDougall-Shackleton, S. A., Osorio-Beristain, M., and Murphy, T. G. (2010). Male bias in the song control system despite female bias in song rate in streak-backed orioles (Icterus pustulatus). Brain Behav. Evol. 76, 168-175. doi: 10.1159/000320971

Hausberger, M., Richard-Yris, M. A., Henry, L., Lepage, L., and Schmidt, I. (1995). Song sharing reflects the social organization in a captive group of European starlings (Sturnus vulgaris). J. Comp. Psychol. 109, 222-241. doi: 10.1037/07357036.109.3.222

Hultsch, H., Mundry, R., and Todt, D. (1999). "Learning, representation and retrieval of rule-related knowledge in the song system of birds," in Learning, eds A. D. Friederici and R. Menzel (Berlin: de Gruyter), 89-111.

Illes, A. E. (2015). Context of female bias in song repertoire size, singing effort, and singing independence in a cooperatively breeding songbird. Behav. Ecol. Sociobiol. 69, 139-150. doi: 10.1007/s00265-014-1827-3

Kleindorfer, S., Evans, C., and Colombelli-Négrel, D. (2014). Females that experience threat are better teachers. Biol. Lett. 10, 20140046. doi: $10.1098 / \mathrm{rsbl} .2014 .0046$

Kleindorfer, S., Evans, C., and Mahr, K. (2016). Female in-nest chatter song increases predation. Biol. Lett. 12:20150513. doi: 10.1098/rsbl.2015.0513

Kleindorfer, S., Evans, C., Mihailova, M., Colombelli-Négrel, D., Hoi, H., Griggio, M., et al. (2013). When subspecies matter resident Superb Fairy-wrens (Malurus cyaneus) distinguish the sex and subspecies of intruding birds. Emu 113, 259-269. doi: 10.1071/MU12066

Kroodsma, D. E. (1976). Reproductive development in a female songbird: differential stimulation by quality of male song. Science 192, 574-575. doi: 10.1126/science.192.4239.574

Langmore, N. E. (1998). Functions of duet and solo songs of female birds. Trends Ecol. Evolut. 13, 136-140. doi: 10.1016/S0169-5347(97)01241-X

Langmore, N. E., Davies, N. B., Hatchwell, B. J., and Hartley, I. R. (1996). Female song attracts males in the alpine accentor Prunella collaris. Proc. R. Soc. Lond. B. Biol. 263, 141-146. doi: 10.1098/rspb.1996.0022

Langmore, N. E., and Mulder, R. A. (1992). Novel context for bird song: predator calls prompt male singing in the kleptogamous Superb Fairy-Wren, Malurus cyaneus. Ethology 13, 136-140. doi: 10.1111/j.1439-0310.1992.tb 00828.x

Law, E., and Ahn, L. V. (2011). Human computation. Synth. Lect. Artif. Intellig. Mach. Learn. 5, 1-121. doi: 10.2200/S00371ED1V01Y201107AIM013

Lobato, M., Vellema, M., Gahr, C., Leitao, A., De-lima, S., Geberzahn, N., et al. (2015). Mismatch in sexual dimorphism of developing song and song control system in blue-capped cordon-bleus, a songbird species with singing females and males. Front. Ecol. Evol. 3:117. doi: 10.3389/fevo.2015. 00117

MacDougall-Shackleton, S. A., and Ball, G. F. (1999). Comparative studies of sex differences in the song-control system of songbirds. Trends Neurosci. 22, 432-436. doi: 10.1016/S0166-2236(99)01434-4

Marler, P., and Slabbekoorn, H. (2004). Nature's Music: The Science of Birdsong. San Diego: Elsevier Academic Press.

Mulder, R. A. (1995). Natal and breeding dispersal in a co-operative, extra-groupmating bird. J. Avian. Biol. 26, 234-240. doi: 10.2307/3677324

Mulder, R. A. (1997). Extra-group courtship displays and other reproductive tactics of superb fairy-wrens. Aust. J. Zool. 45, 131-143. doi: 10.1071/ZO96041

Mulder, R. A., Dunn, P. O., Cockburn, A., Lazenby-Cohen, K. A., and Howell, M. J. (1994). Helpers liberate female fairy-wrens from constraints on extra-pair mate choice. Proc. R. Soc. Lond. Biol. 255, 223-229. doi: 10.1098/rspb.1994.0032 
Nowicki, S., Searcy, W., and Peters, S. (2002). Brain development, song learning and mate choice in birds: a review and experimental test of the "nutritional stress hypothesis". J. Comp. Physiol. A 188, 1003-1014. doi: 10.1007/s00359002-0361-3

Odom, K. J., Hall, M., Riebel, K., Omland, K. E., and Langmore, N. E. (2014). Female song is widespread and ancestral in songbirds. Nat. Commun. 5:3379. doi: $10.1038 /$ ncomms 4379

Pavlova, D. Z., Pinxten, R., and Eens, M. (2010). Age-related changes of song traits in female European Starlings (Sturnus vulgaris). Anim. Biol. 60, 43-59. doi: 10.1163/157075610X12610595764138

Pfenning, A. R., Hara, E., Whitney, O., Rivas, M. V., Wang, R., Roulhac, P. L., et al. (2014). Convergent transcriptional specializations in the brains of humans and song-learning birds. Science 346:1256846. doi: 10.1126/science. 1256846

Pilowsky, J. A., and Rubenstein, D. R. (2013). Social context and the lack of sexual dimorphism in song in an avian cooperative breeder. Anim. Behav. 85, 709-714. doi: 10.1016/j.anbehav.2013.01.012

Price, J. J. (1998). Family-and sex-specific vocal traditions in a cooperatively breeding songbird. Proc. R. Soc. Lond. B. Biol. 265, 497-502. doi: 10.1098/rspb.1998.0322

Price, J. J. (2009). Evolution and life-history correlates of female song in the New World blackbirds. Behav. Ecol. 20, 967-977. doi: 10.1093/beheco/arp085

Price, J. J. (2015). Rethinking our assumptions about the evolution of bird song and other sexually dimorphic signals. Front. Ecol. Evol. 3:40. doi: $10.3389 /$ fevo.2015.00040

Riebel, K. (2003). The 'mute' sex revisited: vocal production and perception learning in female songbirds. Adv. Study Behav. 33, 49-86. doi: 10.1016/S00653454(03)33002-5

Riebel, K., Hall, M. L., and Langmore, N. E. (2005). Female songbirds still struggling to be heard. Trends Ecol. Evol. 20, 419-420. doi: 10.1016/j.tree.2005.04.024

Rowley, I. C. R. (1965). The life history of the superb blue wren, Malurus cyaneus. Ети 64, 251-297. doi: 10.1071/MU964251
Rowley, I. C. R., and Russell, E. (1997). Fairy-Wrens and Grasswrens: Maluridae. Oxford: Oxford University Press.

Schmidt, K. L., Moore, S. D., MacDougall-Shackleton, E. A., and MacDougallShackleton, S. A. (2013). Early-life stress affects song complexity, song learning and volume of the brain nucleus RA in adult male song sparrows. Anim. Behav. 86, 25-35. doi: 10.1016/j.anbehav.2013.03.036

Schwabl, H., Dowling, J., Baldassarre, D. T., Gahr, M., Lindsay, W. R., and Webster, M. S. (2015). Variation in song system anatomy and androgen levels does not correspond to song characteristics in a tropical songbird. Anim. Behav. 104, 39-50. doi: 10.1016/j.anbehav.2015.03.006

Spencer, K. A., Wimpenny, J. H., Buchanan, K. L., Lovell, P. G., Goldsmith, A. R., and Catchpole, C. K. (2005). Developmental stress affects the attractiveness of male song and female choice in the zebra finch (Taeniopygia guttata). Behav. Ecol. Sociobiol. 58, 423-428. doi: 10.1007/s00265-005-0927-5

Wickler, W., and Sonnenschein, E. (1989). Ontogeny of song in captive duetsigning slate-coloured boubous (Laniarius fumebris). A study in birdsong epigenesis. Behaviour 111, 220-233. doi: 10.1163/156853989X00673

Williams, H. (1990). Models for song learning in the zebra finch: fathers or others? Anim. Behav. 39, 745-757. doi: 10.1016/S0003-3472(05)80386-0

Yamaguchi, A. (2001). Sex differences in vocal learning in birds. Nature 411, 257-258. doi: $10.1038 / 35077143$

Conflict of Interest Statement: The authors declare that the research was conducted in the absence of any commercial or financial relationships that could be construed as a potential conflict of interest.

Copyright (๑) 2016 Evans and Kleindorfer. This is an open-access article distributed under the terms of the Creative Commons Attribution License (CC BY). The use, distribution or reproduction in other forums is permitted, provided the original author(s) or licensor are credited and that the original publication in this journal is cited, in accordance with accepted academic practice. No use, distribution or reproduction is permitted which does not comply with these terms. 